\title{
Study on the Hermeneutics and Esthetics Theory of Umberto Eco*
}

\author{
Qianqian $\mathrm{Su}$ \\ College of Humanities \& Sciences \\ Northeast Normal University \\ Changchun, China
}

\begin{abstract}
Mr. Umberto Eco, a well-known Italian scholar and European public intellectual, has made great achievements in literature, art and aesthetics. Also, as an author of academic novels, he has explained his academic attainments. This paper takes the hermeneutics theory of Italian scholar Umberto Eco as the research object and focuses on his theoretical propositions such as "interpretation and over-interpretation" and "textual intention", and then the issues of "over-interpretation" and "usage" of text are put forward. This will help us to introspectall kinds of criticism under the background of post-modernism and bring order to the puzzling work from many readers, thus correct the chaotic phenomenon in the contemporary literary criticism.
\end{abstract}

Keywords-Umberto Eco; over-interpretation; textual intention

\section{INTRODUCTION}

As an academic writer and senior scholars in the field of art and aesthetics, Mr. Eco has proposed the "Open Work" theory in the second half of the 20th century to the European avantgarde art and encouraged the diversification of contemporary art in Europe and the openness of the meaning. At the end of the 20th century, however, he was deeply worried about some extreme ideas in contemporary literary criticism, especially the "extreme" deconstruction of Silas Miller and Paul Derman. This approach, he argues, is akin to "giving the reader the right to read the text without restraint", "a clumsy and absurd appropriation of the notion of infinite derivative meaning"[1]He challenged that and tried to establish the boundaries of interpretation. In the "Dana lecture" at Cambridge University, under the theme of "interpretation and over-interpretation", he had an ideological confrontation with Richard Rorty and Jonathan Kale and other contemporary literary critics. He also puts forward the "textual intention" as an objective standard to test the validity of interpretation. Eco's ideas about excessive interpretation and interpretation under the postmodern context of western cultural criticism not only bring order out of chaos, but also can be a standard in the rambling criticism in China's contemporary art and culture creation and new media.

*This paper is the serial results of the key social science funding project of the 13th five-year plan of Jilin Education Department --- A study on the duality of "misreading" in traditional literary texts in the age of visualization, Project no. 2016[512].

\section{OPPOSING "OVER-INTERPRETATION"}

There are often two extreme ideas about the interpretation of the original work. One is to try to establish a single standard for textual interpretation, which often leads to "insufficient interpretation". Another approach, which seeks to find the possibility of infinite interpretation of the text, often leads to what Eco calls "over-interpretation."

It is not easy to determine which interpretation is an "appropriate interpretation", but it is not hard to see which interpretation is a "bad" interpretation. At the Dana lecture at Cambridge University, the pragmatists represented by Richard Rorty confronted everything from a pragmatic point of view. They believe that ideas, concepts, and other ideological forms are merely tools for achieving certain purposes, rather than means for expressing the nature of the world. In the eyes of pragmatists, "anything that anyone does is a kind of 'usage'. To interpret the nature of something, etc. is simply the different ways in which things are used." "With certain purposes and needs we have certain approaches. We should not go beyond specific purposes and needs to seek unnecessary precision or universality. "[2] Such pragmatism will inevitably lead them to read and interpret works from the standpoint and perspective of their own needs, disregarding the author's intention and the text's intention, which will make them go to the extreme of merely using the texts.

Eco rejected Rorty's arguments as "over-interpretation". He believes that the interpretation of the text from Rorty's pragmatic view will inevitably lead to an unconstrained interpretation of the text. Pragmatists' interpretation from their own intention is bound to ignore the background of the text and the intention of the text itself. Once the text leaves the author's intention and the specific context of writing, it will float in a vacuum of infinite possibilities of interpretation. In Eco's opinion, the interpretation of works that completely ignores the author's intention and textual intention and simply starts from the needs of readers can be called the "usage" of works. To these users, the work is not presented in a way in accordance with their original appearance, but in a way to meet the needs of readers. They can mean everything that readers need. As long as the interpretation meets the needs of the users and can serve their goals, the interpretation can be called "appropriate". In fact, the fundamental reason for the "use" of works is that readers take their own identity, position and 
status as the starting point of interpretation. They regard the works as the tools to realize their realistic purposes. And the works for the users are simply a kind of identity. In the second half of the 20th century, the movement of widening the meaning of the classics has a clear flavor of using the texts. These theorists who want to broaden the classics argue that the social ideas on which some traditional classics and related research methods are formed and based are no longer dominant. New categories of classics should be established to involve women and some previously oppressed races. Schools of Feminism, Marxism, Post-Colonialism and New Historicism have emerged and different voices are put forward in the interpretation and study of literary classics. However, no matter how different their theoretical research methods and research categories are, their research purposes and starting points are very similar--researchers of all schools have studied literary classics from their own political standpoint and social status in order to come to a strong conclusion conducive to themselves. Their study on literary classics has in essence become what Eco calls "usage".

In addition, Eco also found the root of "over-interpretation" from classical mysticism. In the eyes of mystics, the text is fully open, in which readers can find endless connections. Those texts that are trying to be definitive are "misplaced universes"; Anyone who tries to impose the reader's intention on the author's will can be a "superman" of truth. In mysticism, "the reader's glorious mission is to discover. Text can express anything, but it just can't express what the author wants. The preset meaning of the text "is not its real meaning; the real meaning is the deeper meaning."The 'real reader' is the one who understands that the secret of the text is 'nothing'.[1] Such an interpretation of the text cannot be included in the "appropriate interpretation" at all but is an indisputable "usage" of the text.

\section{PROPOSAL OF "TEXTUAL INTENTION"}

In fact, Eco, who pays full attention to the important role of readers in the process of generating textual meaning, does not want to set up some kind of "criterion" for readers' interpretation. His essential intention is to propose a concept that establishes an appropriate dimension for various interpretations, which is "the Textual Intention". Eco tries to maintain a dialectical relationship between "author's intention" and "reader's intention", and what can maintain the balance between the two is "textual intention"."Textual intention" exists between the unreachable author's intention and the controversial reader's intention. It makes some unwarranted interpretations become obvious and self-defeating immediately. It is the objective intention of the text itself. It cannot be seen directly from the text, nor is it clearly and comprehensively anticipated by the author in the process of the creation. It is inferred by the reader from his own place. Some textual intention may not be clearly aware of by the author in the process of creation, but the existence of text itself indicates its rationality. According to Eco, one of the positive effects of readers is to speculate about the intention of the text. The reader guesses the intention of the text by reading and interpreting the text. In a wide variety of interpretations, only those that can accord with the textual intention can become appropriate interpretations, and those that exceed the limits can be considered to be bad or reluctant interpretations. More extreme one is the usage of texts.

Any interpretation of the text involves the intention of the text itself, the "expected horizon" of a specific group of readers, and the cultural background needed to understand the text. This means that the rationality of interpretation should be judged not only by the factors of readers themselves, but also by whether such interpretation conforms to the text and its broad cultural background. When readers deal with literary texts, they are not only dealing with the perceptual materials provided by the texts, but also dealing with the various interpretations on this issue before. The result of the readers' interpretations cannot be tested through the discussion between the readers. Therefore, it is necessary to find a suitable standard for readers' interpretation. With this standard, we can judge which interpretations are more appropriate than others. In Echo's view, the so-called standard is to test the reader's interpretation in the overall coherence of the text. Because every work is an organic whole and there must be an organic connection between the parts of the work. If the reader's interpretation of one part contradicts that of the rest of the work, it is necessary to correct his interpretation. This interpretation cannot be confirmed by other parts of the text. It is an inappropriate interpretation and should be abandoned. If the reader's interpretation has no contradiction with, can connect with, and can be testified by the rest part of the text, it can be regarded as appropriate interpretations that conforms to the textual intention.

In addition, the interpretation of "textual intention" must refer to the circumstances where the author does the creation to a certain extent in order to become an appropriate and effective interpretation. Mr. Eco cites as an example the writings of Italy's former prime minister, Alder Moro, who was kidnapped by the extremist group BrigateRosse. In 1978, former Italian prime minister Alder Moro was kidnapped by the far-left terrorist group BrigateRosse in exchange for the group's core leader, Rinaldo Cujo. Within 55 days of his abduction, Moro had sent 18 letters to the Italian government, in hope that the government will negotiate and exchange hostages as the group has demanded. But the letters were deemed by the Italian government to have been written by Moro under duress, not by Moro's intention to defend the government. It was ignored by the government. In the end, Moro was executed by the extreme group and became a political casualty. In this case, the Italian government ignored the intention of the "text" itself and the specific circumstances in which the "author" Moro was writing, but analyze the text written a politician unreasonably from an ideological standpoint, which led to the extreme consequences of Moro's death. In this way, readers should see clearly the real requirements of the text and the realistic situation of the author's creation, reasonably grasp the "textual intention" and find out the "model author" behind the text. In this way, the readers' interpretations will not become a kind of meaningless "speculation".

\section{Current VAlue of Eco's Hermeneutics}

As both a theorist and a writer of novels, Eco pays great attention to the interpretation activities. On the one hand, as a 
theoretical researcher, he supports the active role of readers, advocates placing readers in an important position, and tries to achieve his own theoretical point of view through the creations of the novel. On the other hand, as the creator of the novel, he put his hermeneutics theory into practice. He challenges those theories with "extreme" deconstruction ideas and proposes the concept of "textual intention" to maintain a balance between the author and the reader. Eco's concept of "textual intention" aims to establish an appropriate standard for various interpretations and maintain a dialectical relationship between "author intention" and "reader intention". In his opinion, the criterion to judge whether the reader's interpretation is appropriate is to test the reader's interpretation in the overall coherence of the text. Only those that are relevant to other parts of the text and can be confirmed by other parts of the text without affecting the overall coherence are legitimate interpretations; on the contrary, it is "over-interpretation". In this way, the text is not only a tool to judge the rationality of interpretations, but an object gradually established in the process of proving its own legitimacy. It is not hard to find out that Eco's hermeneutics theory is based on works and texts, investigating the interpretation and its rationality. The aspect of hermeneutics that advocates interpretation has an epistemological significance and plays an important transitional role in the transformation of hermeneutics from philosophy field to literature field. And it is of great enlightening significance to the reception aesthetics and readers' reactive criticism. The opposition to excessive interpretation in his theory reflects a moderate and dialectical attitude, which is a further supplement to Eco's early hermeneutics and reflects the consistency and coherence of his hermeneutics.

\section{CONCLUSION}

In a word, the definition of "textual intention" by Eco is essentially concerned with the "degree" of literary interpretation and evaluation. Eco's emphasis on the historical dimension of interpretation is presented in an epistemological form. He thinks that the value of an artistic theory is not to judge and analyze the artistic styles and aesthetic value in its time, but to presume and analyze the overall direction of the time and to point out the tendency of cultural development. In his opinion, the symbol of artistic style is related to specific culture and the connotation of the ideology. One of the great significance of the symbolic structure of each art form is to reveal the way that science or culture "observed reality" at that time, that is, art reflects reality. Eco's ideas about interpretation and excessive interpretation not only bring order to the western cultural criticism under the context of postmodern eras, but also have its meaning in standardizing China's contemporary art and culture creation and the rambling criticism of new media.

\section{REFERENCES}

[1] Umberto Eco, Italy. Interpretation and Overinterpretation [C]. Translated by Wang Yugen. Beijing: Joint Publishing, 1997. pp. 9, 42. (意大利) 安贝托・艾柯. 诠释与过度诠释 [C]. 王宇根 译。北 京: 三联书店，1997.第9、42 页.
[2] Richard Rorty, Between the Pragmatic Processes, (Italy) Umberto Eco: Interpretation and Overinterpretation [C]. Wang Yugen. Beijing: the Joint Publishing company LTD., 1997), pp. 113, 101. 理查德・罗蒂 《实用主义进程之间》, 见 (意大利) 安贝托 - 艾柯: 诠释与过 度诠释[C]. 王宇根 译. 北京: 三联书店, 1997 年版, 第 101、113 页。 